\title{
On the sensitivity of hard X-ray spectroscopies to the chemical state of $\mathrm{Br}$
}

\author{
Amélie Bordage, ${ }^{a \ddagger}$ Mátyás Pápai, ${ }^{a}$ Norbert S. Sas,${ }^{a}$ Jakub Szlachetko, ${ }^{b c}$ Maarten Nachtegaal ${ }^{b}$ and \\ György Vankóo*
}

\author{
Received Xth XXXXXXXXXX 20XX, Accepted Xth XXXXXXXXX 20XX \\ First published on the web Xth $X X X X X X X X X X 200 X$ \\ DOI: 10.1039/b000000x
}

The sensitivity of the $1 s$ X-ray emission and high-energy-resolution fluorescence-detected X-ray absorption spectroscopies (XES and HERFD-XAS) to resolve the variations of the chemical state (electronic structure and local coordination) of $\mathrm{Br}$ has been investigated for a selected set of compounds including $\mathrm{NaBrO}_{3}, \mathrm{NH}_{4} \mathrm{Br}$ and $\mathrm{C}_{2} \mathrm{H}_{4} \mathrm{Br}_{2}$ (1,2-dibromoethane). For the Br K-edge XAS, employing the HERFD mode significantly increases the energy resolution, which demonstrates that with a crystal spectrometer used as detector the absorption technique becomes a more powerful analytical tool. In the case of XES, the experimental results as well as the density functional theory (DFT) modeling both show that the chemical sensitivity of the main $1 s$ diagram emission lines $\left(\mathrm{K} \alpha_{1,2}\right.$ and $\left.\mathrm{K} \beta_{1,3}\right)$ is rather limited. However, the valence-to-core $\left(\mathrm{K} \beta_{2}\right)$ region of XES displays significant shape and intensity variations, as expected for transitions having the same final states as those of photoemission spectroscopy. The spectra are in good agreement with the molecular orbital description delivered by DFT calculations. Calculations for an extended series of $\mathrm{Br}$ compounds confirm that valence-to-core XES can serve as a probe for chemical analysis, and, being a hard X-ray photon-in/photon-out technique, it is particularly well-suited for in situ investigations of molecular transformations, even on the ultrafast time scales down to femtosecond time resolution.

\section{Introduction}

Hard X-ray spectroscopies possess several attributes, including element and orbital selectivity, bulk sensitivity, flexibility of the sample environment due to the high penetration depth, that make them attractive for materials science, chemical, physical, geological and biological research. Among them, X-ray absorption spectroscopy (XAS) is widely used to characterize the structure and the chemical state (local symmetry, coordination number, oxidation state, etc.) of a chosen element in the system of interest. While XAS probes only the empty electron states of the absorbing atom, X-ray emission spectroscopy (XES) complements this by probing the occupied states. Accordingly, XES can bring detailed information on the electronic structure, and can be utilized to solve questions concerning molecular orbitals, the nature of the bonding, the nature of the neighboring atoms and the valence and spin state of the absorbing atom ${ }^{1-8}$.

The interpretation of XAS and XES spectra is often done with the fingerprint approach: information is deduced from

\footnotetext{
${ }^{a}$ Wigner Research Centre for Physics, Hungarian Academy Sciences, H-1525 Budapest, P.O.B. 49., Hungary. Fax: 003613959151 ; Tel: 00361392222 -1736; E-mail:vanko.gyorgy@wignermta.hu

${ }^{b}$ Paul Scherrer Institute, Swiss Light Source,5232 Villigen, Switzerland.

${ }^{c}$ Jan Kochanowski University, Kielce, Poland.

$\ddagger$ Present address: Institut Néel, CNRS et Université Joseph Fourier, BP 166, F-38042 Grenoble Cedex 9, France.
}

the comparison between the spectrum of the compound of interest and reference systems. However, this approach obviously limits the interpretation and the fine details of the local and electronic structure remains out of reach. This restriction can nevertheless be overcome by coupling the experiments with a theoretical determination of the spectrum, based either on first-principles calculations based on the density functional theory (DFT) or on multiplet calculations ${ }^{9}$ based on the ligand field multiplet (LFM) theory, which enable us to achieve a reliable theoretical modeling of the spectrum. In the case of XAS, the combination of experiment and theory has almost become a routine for both the main $\mathrm{K}$ edge and pre-edge (see e.g. Refs. ${ }^{9-29}$ ), and more and more XES investigations are also done using the support from theory (see e.g. ${ }^{3-7,30-32}$ ). From an experimental point of view, XES requires a wavelengthdispersive spectrometer based on analyzer crystals. Such an instrument can also open up the application of high-resolution XAS when installed on a conventional absorption beamline: a fluorescence-yield XAS spectra can be recorded through the crystal spectrometer with an energy bandwidth smaller than the core-hole lifetime broadening ${ }^{33}$. This so-called high-energy-resolution fluorescence detected XAS (HERFD$\mathrm{XAS})^{2,17,34}$, not only enables us to get better resolved features $^{2,33,35}$ and better signal-to-noise ratio, but it can also filter off unwanted signals from other elements ${ }^{19,36}$. HERFD-XAS has been thus successfully used for instance in studies at the K 
pre-edge of $3 d$ elements ${ }^{2,12,15,19,20,37}$, or at the Dy L edge ${ }^{33,35}$, $\mathrm{S} K$ edge ${ }^{38}$, and the $\mathrm{L}$ edge of $\mathrm{Pb}^{39}, \mathrm{Pt}^{40,41}$, and $\mathrm{Ce}^{42}$.

Bromine-containing compounds have been intensively investigated by XAS during the last 40 years ${ }^{43,44}$, in order to learn more about their fundamental properties ${ }^{45-51}$, their multi-electron excitations ${ }^{52,53}$, or to address geological and environmental problems ${ }^{54,55}$. They represent an important family of natural and synthetic compounds. In nature, they are often found in the marine environment ${ }^{56}$; for instance, bromoform $\mathrm{CHBr}_{3}$ (which is also used for water treatment) is produced by edible algae and phytoplankton ${ }^{57}$. The industrial use of bromine-containing compounds ranges from additive in leaded petrol (antiknock agent) ${ }^{58}$ through pesticides and fumigants for agriculture to radiopaque acrylic bone cement for surgery ${ }^{59}$. They also used to be widely employed as fireretardants ${ }^{60}$. As many of these Br-compounds are now considered as persistent organic pollutants, they became a major environmental and health issue ${ }^{61-64}$. In chemistry laboratories and chemical industry, bromine is a significant and wildly present element, used as a component of Grignard reagents (alkyl- or aryl-Mg bromides) ${ }^{65}, \mathrm{pH}$ indicators (bromothymol blue), etc. Despite this lengthy list, to our knowledge, no systematic study of Br-compounds has yet been done to exploit the opportunities offered by the use of a high-resolution crystal spectrometer to characterize the $\mathrm{Br}$ chemical state, in particular with XES. While such measurements might not be of utmost importance in static experiments because of the availability of other and simpler techniques, studying ultrafast processes, for instance, photodissociation or photolysis of Br-bearing systems ${ }^{66-68}$, could benefit from a novel timeresolved tool. Such processes have already been investigated by time-resolved XAS and X-ray scattering ${ }^{67,68}$, however, recent works on other systems have demonstrated that XES, especially when combined with these other tools, can lead to a better understanding of the molecular transformations and the nature of the intermediates in ultrafast pump-probe experiments ${ }^{69-73}$. Our main motivation was to find out which of the $1 s$ emission lines offer sufficient chemical sensitivity for such studies.

In the present work three Br-compounds $\left(\mathrm{C}_{2} \mathrm{H}_{4} \mathrm{Br}_{2}\right.$, $\mathrm{NH}_{4} \mathrm{Br}$ and $\mathrm{NaBrO}_{3}$ ) were studied with the two simplest techniques accessible with a crystal spectrometer at an X-ray beamline, HERFD-XAS and XES, to obtain benchmarks on the sensitivity of these techniques to the chemical state of $\mathrm{Br}$. The XES experiments were complemented by first-principles calculations based on DFT, which is shown to give insights into the molecular orbital (MO) diagram of the investigated compounds. The agreement obtained between experiments and theory for the three compounds motivated us to extend the calculations to predict the spectra for an additional series of Br-compounds. Finally, the good correspondence of the calculations to the electronic structure is further demonstrated by the excellent agreement between the DFT-predicted transitions involved in the valence-to-core spectrum and the experimental photoemission spectrum (PES) using the example of $\mathrm{Br}_{2}$.

\section{Experimental}

\subsection{Measurements and samples}

Room-temperature $\mathrm{Br} \mathrm{K}$-edge measurements were carried out at the SuperXAS beamline of the Swiss Light Source (SLS, Villigen, Switzerland). The energy of the incident beam was selected using a pair of water-cooled $\mathrm{Si}(111)$ crystals, with a measured resolution of $1.90 \mathrm{eV}$ at the $\mathrm{Br} \mathrm{K}$ edge $(13474 \mathrm{eV})$, and calibrated with an Au foil. The photon flux on the sample was ca. $10^{12}$ photons/s. Total fluorescence yield (TFY) spectra were recorded using a 13-element Ge detector. Highenergy-resolution fluorescence-detected XAS (HERFD-XAS) and XES spectra were recorded using the multi-crystal Xray spectrometer of the beamline: the sample, the $\mathrm{Si}(110)$ analyzer crystals and a PILATUS 100K 2D detector were placed on $1 \mathrm{~m}$ diameter Rowland circles ${ }^{74,75}$. In the case of the $\mathrm{K} \alpha$ lines $\left(\mathrm{K} \alpha_{1} \approx 11925 \mathrm{eV}\right)$, the analyzer crystal was used in an asymmetric mode with the (771) reflection (with an $5.7682^{\circ}$ offset form the (110) direction), and the (880) reflection was chosen for the $\mathrm{Br} \mathrm{K} \beta$ lines $\left(\mathrm{K} \beta_{1} \approx 13291 \mathrm{eV}\right)$. The total energy bandwidth of the setup (including spectrometer and the monochromator for the incident beam) was 2.64 $\mathrm{eV}$ at the $\mathrm{K} \alpha$ lines and $2.9 \mathrm{eV}$ at the $\mathrm{K} \beta$ lines. The HERFDXANES spectra were acquired setting the spectrometer crystal to the maximum of the $\mathrm{K} \alpha_{1}$ or the $\mathrm{K} \beta_{1}$ fluorescence line; the scans were recorded in a step-by-step mode in the range of $13450-13660 \mathrm{eV}$ with a counting time of $3 \mathrm{~s}$ for each measured point. The incident energy for XES measurements were set to $13650 \mathrm{eV}$, i.e. well above the $\mathrm{K}$ edge; the $\mathrm{K} \alpha$ (resp. $\mathrm{K} \beta$ ) emission lines were recorded in the range of $11850-11950 \mathrm{eV}$ (resp. 13260-13480 eV), with a counting time of 3s (resp. $1 \mathrm{~s})$. For a better signal-to-noise ratio in the region of the $K \beta_{2}$ valence-to-core emission lines (13450-13480 eV), additional scans were recorded with a counting time of 30 s. No selfabsorption and radiation damages were observed during the experiments. The XAS spectra were background corrected and normalized to the edge jump, and the area of the coreto-core XES scans were normalized to unity.

The time allotted for this experiment permitted us to study only three samples (Table 1) with the above techniques. The investigated compounds include $1,2-\mathrm{C}_{2} \mathrm{H}_{4} \mathrm{Br}_{2}$ (supplied by Fluka), $\mathrm{NH}_{4} \mathrm{Br}$ (supplied by Gyógyszer Alapanyag Készítő Vállalat), and $\mathrm{NaBrO}_{3}$ (supplied by AlfaAesar). Due to a light pigmentation of the $\mathrm{C}_{2} \mathrm{H}_{4} \mathrm{Br}_{2}$ liquid, it was distilled under vacuum before the measurements. Their structures are given in table 1 , along with the oxidation state and coordination 
number of $\mathrm{Br}$ in the investigated samples. They were chosen to represent the different types of Br-compounds (respectively covalent, ionic and molecular ion). For $\mathrm{NH}_{4} \mathrm{Br}$ and $\mathrm{NaBrO}_{3}$, measurements were performed on $5 \mathrm{~mm}$-pellets of the solid compound, which crystallizes respectively in the $P m 3 m^{76}$ and $P 2_{1} 3^{77}$ space groups. The liquid $\mathrm{C}_{2} \mathrm{H}_{4} \mathrm{Br}_{2}$ sample was enclosed in a $1 \mathrm{~mm}$ diameter Kapton tube, with a wall thickness of $25 \mu \mathrm{m}$. TFY-XAS and HERFD-XAS measurements were performed on pellets for $\mathrm{NH}_{4} \mathrm{Br}$ and $\mathrm{NaBrO}_{3}$ (diluted with cellulose), except for the case of $\mathrm{K} \beta$-XES measurements where pure compounds were used.

\subsection{Computational details}

The calculations of the XES spectra were carried out with the ORCA program package ${ }^{78}$. The detailed theory of the calculation will not be discussed here, as it was already described by Neese and co-workers ${ }^{5}$. Structures of the studied compounds were optimized using the B3LYP hybrid density functional method ${ }^{79,80}$ in combination with the TZVP basis set ${ }^{81}$. The method of the direct inversion of the iterative subspace (DIIS) ${ }^{82}$ was applied to the self-consistent field (SCF) part of the calculation. The X-ray emission spectra were computed in a one-electron approach; this includes the calculation of transition energies as the differences of core- or valence orbital energies. Spin-orbit coupling was included for the calculation of the $\mathrm{K} \alpha$ and $\mathrm{K} \beta$ emission spectra. Electric and magnetic dipole as well as electric quadrupole transitions were considered in the calculations. The integral accuracy was set to 7.0 for bromine atoms in order to achieve a more accurate description. A broadening was applied to the calculated transitions through a pseudo-Voigt function, with a $1 \mathrm{eV}$ FWHM contribution from the Lorentzian function and $2.5 \mathrm{eV}$ FWHM from the Gaussian one. (For the $\mathrm{K} \alpha$ and $\mathrm{K} \beta_{1,3}$ core-to-core XES lines $2 \mathrm{eV}$ and $4 \mathrm{eV}$ were used to better match the experimental spectra.) The molecular orbital (MO) diagram was also constructed from the Kohn-Sham one-electron orbital energies, and it was visualized using the MOanalyzer program ${ }^{83}$.

\section{Results and discussion}

\subsection{X-ray absorption spectroscopy}

The Br K-edge spectra recorded for $\mathrm{C}_{2} \mathrm{H}_{4} \mathrm{Br}_{2}, \mathrm{NH}_{4} \mathrm{Br}$ and $\mathrm{NaBrO}_{3}$ in three different detection modes are displayed in figure 1. Prior to the variations of the spectral features between the three compounds, the first obvious observation is that the resolution at the conventional total fluorescence yield (TFY) and the high-energy resolution fluorescence detection (HERFD) detection is very different. Spectral features barely visible in the TFY-XAS scans appear very clearly in the HERFD-XAS ones, for both $\mathrm{K} \alpha$ or $\mathrm{K} \beta$ detections. This improved resolution stems from the narrow bandwidth of the XES spectrometer, which filters off many final state interactions, as it has been already extensively described ${ }^{2,33,39,84}$. The relevant lifetimes should illuminate this: In TFY-XAS, the final state has a $1 s$ core-hole with a lifetime broadening of $2.52 \mathrm{eV}^{85}$. However, in the case of HERFD-XAS, the fluorescence line corresponding to the filling of the $1 s$ core-hole created during the absorption process by a $2 p$ (K $\alpha$-HERFD$\mathrm{XAS})$ or $3 p$ (K $\beta$-HERFD-XAS) electron is recorded. Therefore, in the case of K $\alpha$-HERFD-XAS (resp. K $\beta$-HERFD$\mathrm{XAS}$ ), the final core-hole lifetime broadening is of $1.14 \mathrm{eV}^{85}$ (resp. $1.4 \mathrm{eV}^{86}$ ) because the final core hole is a $2 p$ (resp. $3 p$ ) one. The HERFD detection mode allows obtaining an intermediate value for the broadening, which is manifested in the improved resolution.

The careful comparison of the XAS spectra obtained through different detection modes can be very instructive ${ }^{87}$; in this study we show spectra recorded with three fluorescencebased detection modes. This enables us to compare the variation of the resolution and the relative intensities of the spectral features. The lifetime broadenings of $\mathrm{Br}$ are close for $2 p$ and $3 p$ core holes and, consequently, the $\mathrm{K} \alpha-$ and $\mathrm{K} \beta$ HERFD-XAS spectra are comparable. Nevertheless, in the case of transition metal atoms, the core-hole lifetime broadening of the $\mathrm{K} \alpha$ line is usually much smaller than those of the $\mathrm{K} \beta$ ones ${ }^{85,86}$. Because of this and possibly different finalstate interactions, relevant discrepancies may arise even between $\mathrm{K} \alpha$ - and $\mathrm{K} \beta$-HERFD-XAS.

The variations of the edge spectral features are usually explained with differences in the oxidation state and coordination number of the absorbing atom. Here, for instance, the maximum of the white line of the TFY-XAS spectra is at $13483.33 \mathrm{eV}$ for $\mathrm{NH}_{4} \mathrm{Br}$, whereas the one of $\mathrm{C}_{2} \mathrm{H}_{4} \mathrm{Br}_{2}$ is lower by $3.92 \mathrm{eV}$ and the one of $\mathrm{NaBrO}_{3}$ higher by $0.73 \mathrm{eV}$. The increase of the edge position between $\mathrm{NH}_{4} \mathrm{Br}$ and $\mathrm{NaBrO}_{3}$ is thus consistent with the increasing oxidation state of $\mathrm{Br}$ in these two compounds $(-1$ and +5$)$. However, the white line of the $\mathrm{C}_{2} \mathrm{H}_{4} \mathrm{Br}_{2}$ is found $3.9 \mathrm{eV}$ lower to that of $\mathrm{NH}_{4} \mathrm{Br}$, which shows that this expectation can seriously fail, and thus the edge position may not always reveal the former oxidation state ${ }^{88}$. Nevertheless, another important aspect of the HERFD-XAS measurements arises here: due to the improved resolution, the edge rises steeper in the case of HERFD-XAS than in that of TFY-XAS (Fig. 1). Consequently, the maximum of the first derivative of the spectrum, which is often used to characterize the edge position, is shifted between the TFY-XAS and HERFD-XAS scans, while the positions of the white line maxima are identical (Table 1).

More detailed structural and electronic information cannot be obtained unless a theoretical determination of the spectrum is done. This is beyond the scope of this paper and we will not interpret further the XAS spectra. To conclude this XAS part 
of the study, we wish to point out again that the HERFD mode enables us to obtain better resolved near-edge or extendedrange spectra. Also, the above examples illustrate that whenever a fingerprint analysis is performed in order to deduce the oxidation state or coordination number from the position of the edge or the relative intensities of the spectral features, the same detection mode must be used for both reference and unknown compounds. The edge positions in the presented spectra do not vary proportionally to reflect the formal oxidation state of $\mathrm{Br}$.

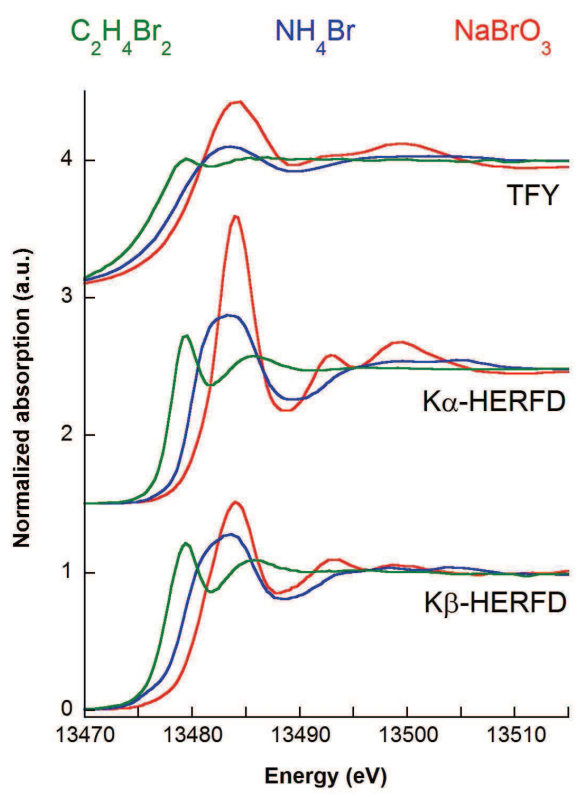

Fig. 1 Normalized $\mathrm{Br}$ K-edge XAS spectra of $\mathrm{C}_{2} \mathrm{H}_{4} \mathrm{Br}_{2}$, $\mathrm{NH}_{4} \mathrm{Br}$ and $\mathrm{NaBrO}_{3}$ recorded in the TFY and HERFD (both $\mathrm{K} \alpha$ and $\mathrm{K} \beta$ ) modes.

\subsection{X-ray emission spectroscopy}

The core hole created during the $1 s$ absorption process is subsequently filled by an electron from higher energy orbitals during an intra-atomic relaxation accompanied by simultaneous X-ray emission; consequently, this process gives access to the occupied electronic states, similarly to photoemission. Besides to the chemically most sensitive valenceto-core ${ }^{4,5,7,32,89-92}$, core-to-core transitions have also proved useful in physical and chemical characterization $2,3,30,38,93,94$. Using a crystal spectrometer, one can record the corresponding X-ray emission spectrum with a good resolution, as illustrated in figure 2 for the case of $\mathrm{NaBrO}_{3}$ (the also displayed theoretical spectrum will be discussed later). The $\mathrm{K} \alpha_{1,2}$ and $\mathrm{K} \beta_{1,3}$ lines (Fig. 2) arise from electric dipole $2 p \rightarrow 1 s$ and $3 p \rightarrow 1 s$ transitions, respectively. Because of the spin-orbit coupling, the $K$ lines are split into two, corresponding to final states in the $p_{3 / 2}$ and $p_{1 / 2}$ levels. The $\mathrm{K} \beta_{5}$ fluorescence lines arise from electric quadrupole $(3 d \rightarrow 1 s)$ transitions, and, as a result, their intensity is much smaller compared to the other (electric dipole) fluorescence lines. The $\mathrm{K} \beta_{2}$ lines result from the filling of the core-hole by a $4 p$ valence electron; therefore, they are referred as valence-to-core transitions. For all the dipolar transitions, the higher the energy of the orbital from which an electron fills the $1 s$ core-hole, the smaller the overlap with the $1 s$ orbital, and, consequently, the smaller the intensity of the corresponding peak.

The peak positions of the XES spectra recorded for the three studied Br-compounds are summarized in table 1 . The $\mathrm{K} \alpha$ spectra, displayed in figure 3, show very little variations: the $\mathrm{K} \alpha_{1}$ peak position of $\mathrm{NH}_{4} \mathrm{Br}$ is at $11924.90 \mathrm{eV}$, that of $\mathrm{C}_{2} \mathrm{H}_{4} \mathrm{Br}_{2}$ is $0.28 \mathrm{eV}$ higher, and the one of $\mathrm{NaBrO}_{3}$ is 0.22 $\mathrm{eV}$ higher. The $\mathrm{K} \beta_{1,3}$ lines fall also very close, as seen in figure 4: the $\mathrm{K} \beta_{1}$ line of $\mathrm{NH}_{4} \mathrm{Br}$ is at $13290.98 \mathrm{eV}$, the one of $\mathrm{C}_{2} \mathrm{H}_{4} \mathrm{Br}_{2}$ is at $0.33 \mathrm{eV}$ lower and the one of $\mathrm{NaBrO}_{3}$ at $0.22 \mathrm{eV}$ higher. (The energy values for the corresponding $\mathrm{K} \alpha_{2}$ and $\mathrm{K} \beta_{3}$ features follow a very similar trend, as it is obvious from the figures and table 1.) Considering also the large lifetime broadening, we can conclude that these two sets of fluorescence lines $\left(\mathrm{K} \alpha_{1,2}\right.$ and $\left.\mathrm{K} \beta_{1,3}\right)$ do not seem particularly sensitive to the variations in the chemical state of $\mathrm{Br}$. The quadrupolar $(3 d \rightarrow 1 s) \mathrm{K} \beta_{5}$ features (around $13404 \mathrm{eV}$ ) have very low fluorescence yield, and show no relevant chemical shifts; consequently, no valuable information about the chemical state of $\mathrm{Br}$ can be deduced from this part of the spectra.

Nevertheless, the (dipolar) valence-to-core $\left(\mathrm{K} \beta_{2}\right)$ XES spectra display different features in both energy and intensity. This energy shifts of their maxima are again small, but it is accompanied by variations in the intensity and line shape. The peak intensity is the highest for $\mathrm{NH}_{4} \mathrm{Br}$, smaller for $\mathrm{C}_{2} \mathrm{H}_{4} \mathrm{Br}_{2}$ and even smaller for $\mathrm{NaBrO}_{3}$. The spectrum of $\mathrm{C}_{2} \mathrm{H}_{4} \mathrm{Br}_{2}$ is broader, while in the case of $\mathrm{NaBrO}_{3}$, an additional feature is present at around $13457 \mathrm{eV}$, and a highenergy shoulder is visible at about $13471 \mathrm{eV}$. To explore it in more detail, we fitted these spectra with a minimum number of pseudo-Voigt functions ( $\mathrm{pVf}$ ) on a linear background, to obtain a reasonable description of the spectral envelop in the $13452-13480 \mathrm{eV}$ energy region. The spectra and the fits are shown in Fig. 5, where the error bars denote the measured data points and the solid line is the fitted curve. For each spectra, a dashed line shows the main component, and smaller lines, if present, are filled with colour to be more visible. (The FWHM of the Gaussian of the pVfs are between 2.7 and $3 \mathrm{eV}$, while the FWHM of Lorentzian are between 3.8 and $4.1 \mathrm{eV}$.) The spectrum of $\mathrm{NH}_{4} \mathrm{Br}$ looks fairly symmetri$\mathrm{cal}$, and indeed it can be fitted with a single $\mathrm{pVf}$ at 13469.46 $\pm 0.02 \mathrm{eV}$; attempts to fit a second line resulted in unphysical parameters. On the contrary, the spectrum of $\mathrm{C}_{2} \mathrm{H}_{4} \mathrm{Br}_{2}$ is asymmetric. A low energy shoulder is indeed revealed by the 
Table 1 Position of the K-edge XAS and XES main spectral features of $\mathrm{C}_{2} \mathrm{H}_{4} \mathrm{Br}_{2}, \mathrm{NH}_{4} \mathrm{Br}$ and $\mathrm{NaBrO}_{3}$. The maximum of the white line of the XAS spectrum was taken as a reference for the energy position. The XES line positions were obtained by fitting the spectrum with pseudo-Voigt functions.

\begin{tabular}{llll}
\hline & $\begin{array}{l}\mathrm{C}_{2} \mathrm{H}_{4} \mathrm{Br}_{2} \\
\text { liquid }\end{array}$ & $\begin{array}{l}\mathrm{NH}_{4} \mathrm{Br} \\
\text { solid }\end{array}$ & $\begin{array}{l}\mathrm{NaBrO}_{3} \\
\text { solid }\end{array}$ \\
\hline $\begin{array}{l}\text { Oxidation state } \\
\text { Coordination number }\end{array}$ & -1 & -1 & +5 \\
Nature & 1 & 6 & $6 / 3^{*}$ \\
Covalent & Ionic & Molecular ion \\
\hline TFY XAS, white line & & & $13483.33 \pm 0.10$ \\
$\mathrm{~K} \alpha$ HERFD-XAS, white line & $13479.41 \pm 0.05$ & $13483.28 \pm 0.10$ & $13484.06 \pm 0.05$ \\
$\mathrm{~K} \beta$ HERFD-XAS, white line & $13479.44 \pm 0.05$ & $13483.39 \pm 0.10$ & $13484.02 \pm 0.05$ \\
$\mathrm{~K} \alpha_{2}$ & $13479.43 \pm 0.05$ & $11878.31 \pm 0.01$ & $13484.06 \pm 0.05$ \\
$\mathrm{~K} \alpha_{1}$ & $11878.56 \pm 0.01$ & $11924.90 \pm 0.01$ & $11878.58 \pm 0.01$ \\
$\mathrm{~K} \beta_{3}$ & $11925.18 \pm 0.01$ & $13284.18 \pm 0.02$ & $1325.12 \pm 0.01$ \\
$\mathrm{~K} \beta_{1}$ & $13283.88 \pm 0.02$ & $13290.98 \pm 0.01$ & $13284.44 \pm 0.02$ \\
$\mathrm{~K} \beta_{5}$ & $13290.65 \pm 0.01$ & $13404.31 \pm 0.07$ & $13291.20 \pm 0.01$ \\
$\mathrm{~K} \beta_{2}$ valence-to-core maximum & $13404.05 \pm 0.08$ & $13469.46 \pm 0.02$ & $13404.49 \pm 0.07$ \\
\hline$*$ Coordintion & $13469.63 \pm 0.03$ & & $13469.50 \pm 0.02$ \\
\hline
\end{tabular}

* Coordination number of $\mathrm{Br}$ in the $\mathrm{BrO}_{3}{ }^{-}$ion
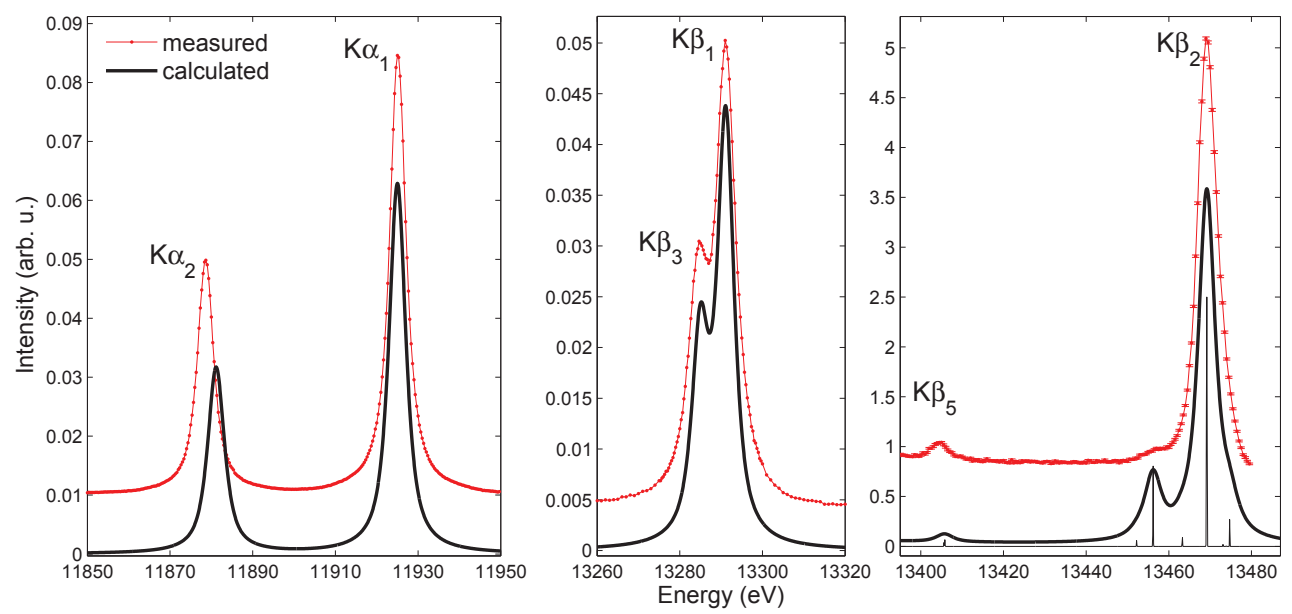

Fig. 2 Experimental (thin line with dots) and calculated (thick line) emission spectrum of $\mathrm{NaBrO}_{3}$. 
fit: two $\mathrm{pVfs}$ were needed, the line positions being 13466.30 \pm 0.14 , and $13469.63 \pm 0.03$, with an intensity distribution of $14 \%: 86 \%$. The main line of $\mathrm{NaBrO}_{3}$ is also asymmetric but on the high-energy side. Since a small low-energy feature is present too, this spectrum required fitting with $3 \mathrm{pVfs}$ at positions $13456.3 \pm 0.8 \mathrm{eV}, 13469.50 \pm 0.02 \mathrm{eV}$, and $13473.6 \pm$ $0.4 \mathrm{eV}$, with intensities as 3\%:88\%: $9 \%$. Based on the above we can conclude that among the hard X-ray emission lines of $\mathrm{Br}$, the valence-to-core emission features seem to show sufficient sensitivity to follow the variations of the chemical state of $\mathrm{Br}$.

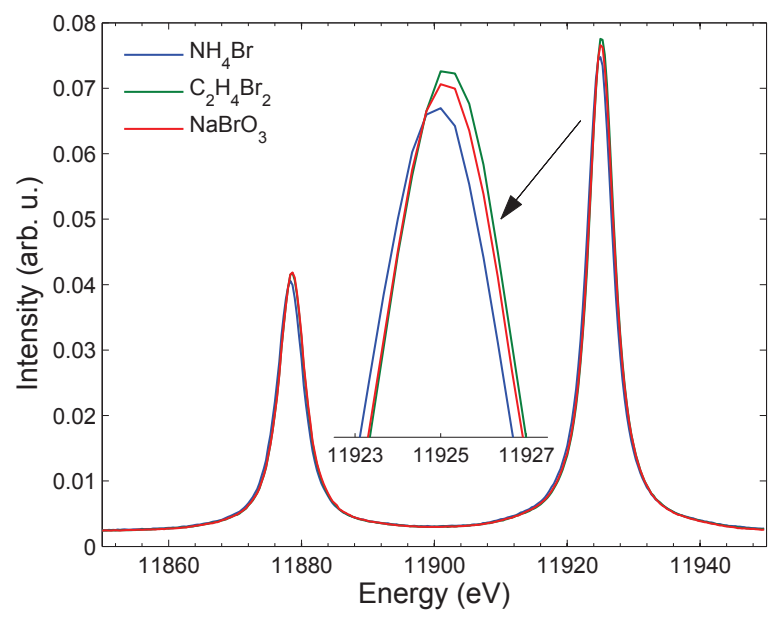

Fig. 3 Normalized $\mathrm{K} \alpha$ XES experimental spectra of $\mathrm{C}_{2} \mathrm{H}_{4} \mathrm{Br}_{2}$, $\mathrm{NaBrO}_{3}$ and $\mathrm{NH}_{4} \mathrm{Br}$.

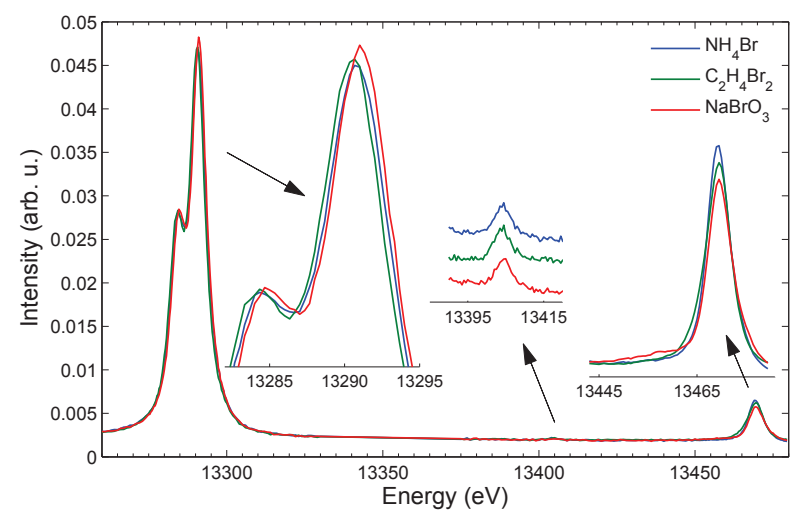

Fig. 4 Normalized $\mathrm{K} \beta$ XES experimental spectra of $\mathrm{C}_{2} \mathrm{H}_{4} \mathrm{Br}_{2}$, $\mathrm{NaBrO}_{3}$ and $\mathrm{NH}_{4} \mathrm{Br}$.

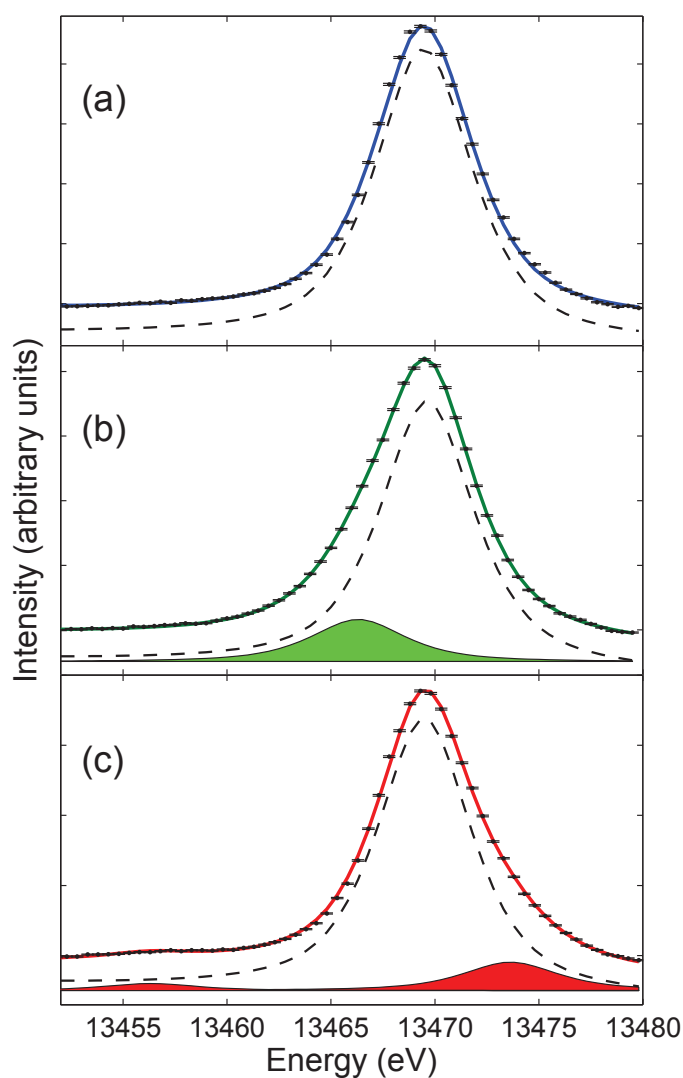

Fig. 5 Fitted $\mathrm{K} \beta_{2}$ spectra of (a) $\mathrm{NH}_{4} \mathrm{Br}$, (b) $\mathrm{C}_{2} \mathrm{H}_{4} \mathrm{Br}_{2}$ and (c) $\mathrm{NaBrO}_{3}$. The data points with error bars represent the experimental spectrum. The solid line is the fitted curve, the dashed line representing its main component and the filled colored lines the smaller contributions. 


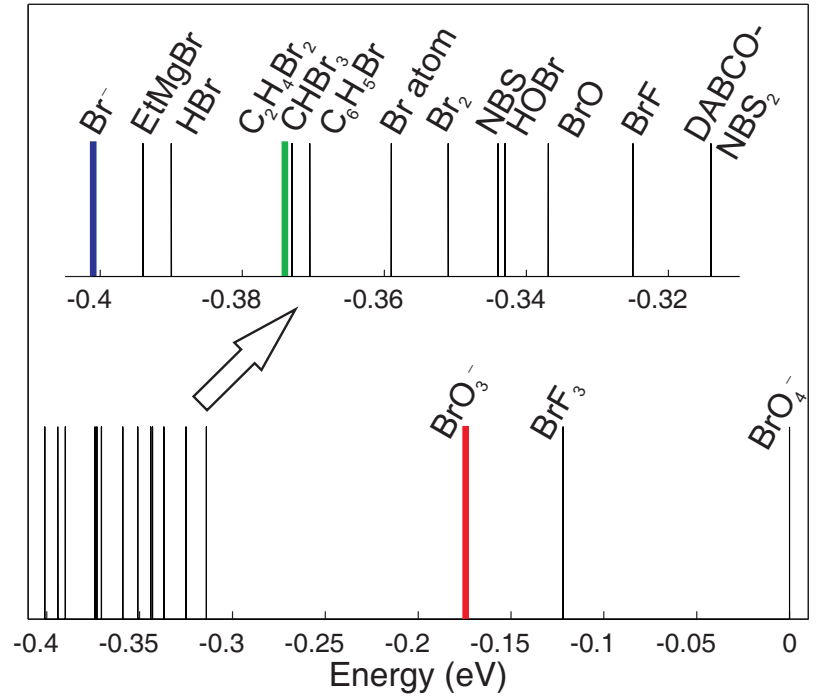

Fig. 6 Calculated relative energy positions of the $\mathrm{Br} \mathrm{K} \alpha_{1}$ emission line for a series of Br-compounds.

\subsection{Theoretical modelling of the XES spectra}

To better understand the chemical shifts and splitting of the fluorescence features, we performed first-principles calculations based on density functional theory (DFT). This approach is more and more often used to interpret the valenceto-core XES spectra of transition metal ions. In the absence of an open valence shell, this is expected to work also for the core-to-core transitions in $\mathrm{Br}$. Indeed, a good agreement was obtained between experiment and theory, as it is illustrated in figure 2 for the case of $\mathrm{NaBrO}_{3}$. The energy positions and relative intensities are well reproduced for the main $\mathrm{K} \alpha_{1,2}$ and $\mathrm{K} \beta_{1,3}$ diagram lines, although the $2 p$ spin-orbit splitting is somewhat underestimated by the calculation, as seen in the splitting of the $\mathrm{K} \alpha$ lines. Also, the absolute energy of the calculated spectra were shifted by $338 \mathrm{eV}(303.5 \mathrm{eV})$ to match the experimental $\mathrm{K} \beta(\mathrm{K} \alpha)$ values. This systematic error of the absolute energy is a well-known effect of DFT and has already been described ${ }^{5,32,95,96}$. The relative energy shifts of the calculated $\mathrm{K} \alpha_{1}$ and $\mathrm{K} \beta_{1}$ lines are presented in figures 6 and 7, respectively, together with a larger set of compounds that will be discussed later. As seen in the figures, the theoretical line positions are in qualitative agreement with the experimental ones, only the $\mathrm{K} \alpha_{1}$ line of $\mathrm{C}_{2} \mathrm{H}_{4} \mathrm{Br}_{2}$ appears too low when compared to the measured value. However, for this spectrum, we cannot exclude a small systematic shift in the experiment, because of the different sample environments, beamline stability issues and limited time. The comparison of the theoretical relative energy of the $K \alpha_{1}$ and $K \beta_{1}$ lines confirm the experimental observation that the $\mathrm{K} \alpha_{1}$ (resp. $\mathrm{K} \beta_{1}$ ) peaks of the three compounds are very close in energy. The variations of

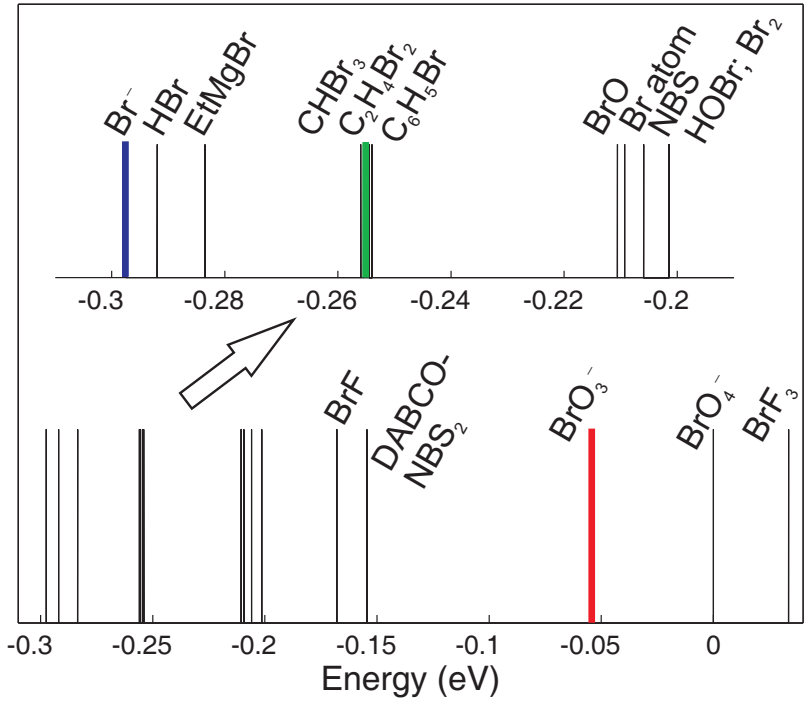

Fig. 7 Calculated relative energy positions of the $\mathrm{Br} \mathrm{K} \beta_{1}$ emission line for a series of Br-compounds.

these fluorescence lines, therefore, apparently cannot provide us with unambiguous spectral signatures on the $\mathrm{Br}$ chemical state, not even with an improved experimental resolution.

We have extended the calculations to a large set of $\mathrm{Br}$ bearing compounds to further test the above observation. The additional $\mathrm{Br}$ compounds have diverse characteristics, and they are of chemical or environmental relevance. The systems include organic bromides: $\mathrm{PhBr}\left(\mathrm{Ph}: \mathrm{C}_{6} \mathrm{H}_{5}\right), \mathrm{CHBr}_{3}$, $\mathrm{BrCCl}_{3}$, and NBS (N-Bromosuccinimide); a charge-transfer complex DABCO-NBS 2 (1,4-diazabicyclo[2.2.2] octane-NBromosuccinimide) with a rather short $\mathrm{Br}-\mathrm{N}$ bond length ${ }^{97}$, and the Grignard reagent $\mathrm{EtMgBr}\left(\mathrm{Et}^{\mathrm{C}} \mathrm{C}_{2} \mathrm{H}_{5}\right)$, to conclude the organic compounds. The compounds $\mathrm{BrF}_{3}, \mathrm{BrO}_{4}^{-}, \mathrm{BrO}$ were selected to test the effect of the oxidation state. Finally, $\mathrm{HBr}$, $\mathrm{Br}_{2}$, the isolated $\mathrm{Br}$ atom and $\mathrm{Br}^{-}$are common forms of $\mathrm{Br}$ in chemical laboratories, and they can also appear in photochemical experiments, thus they are also important for timeresolved spectroscopic studies. The relative positions of $\mathrm{K} \alpha_{1}$ and $\mathrm{K} \beta_{1}$ main peaks are displayed in figures 6 and 7, together with the three compounds discussed before $\left(\mathrm{C}_{2} \mathrm{H}_{4} \mathrm{Br}_{2}, \mathrm{NH}_{4} \mathrm{Br}\right.$, $\mathrm{NaBrO}_{3}$ ). The calculated positions of these peaks show an obvious correlation with the oxidation state of $\mathrm{Br}$; however, they remain in a window of $0.4 \mathrm{eV}$ in both cases $\left(\mathrm{K} \alpha_{1}\right.$ and $\mathrm{K} \beta_{1}$ ), thus confirming again our previous conclusion that the $\mathrm{K} \alpha$ and $\mathrm{K} \beta$ lines are not sensitive enough to resolve the variations in the $\mathrm{Br}$ chemical state. The required experimental resolution is indeed not achievable to discriminate these features, mainly because of the large lifetime broadening. Nevertheless, we can also conclude that the present level of theory seems to have the potential to predict core-to-core XES spectra for cases where the electronic structure can be described 
with the single-electron approximation.

The experimental (Fig. 5) and calculated (Fig. 8) valenceto-core emission features demonstrate the great interest of this part of the XES spectrum to characterize the chemical state of Br. By comparing the stick diagram from the fit of the experiment in Fig. 8b with the theoretical one in Fig. 8c, the similarity of the observed and calculated transitions is obvious. For the $\mathrm{Br}^{-}$, two very close transitions $(\Delta E<0.4 \mathrm{eV})$ are predicted by the theory; the splitting of these two lines remain unresolved in the experiment, and the spectra has apparently a single line, which is expected for such a very small splitting and an order of magnitude larger line broadening. In the case of $\mathrm{C}_{2} \mathrm{H}_{4} \mathrm{Br}_{2}$, a low-intensity satellite is expected from the theory at $2 \mathrm{eV}$ below the main line, and indeed, a lowerenergy $(-3.3 \pm 0.2 \mathrm{eV})$ small-intensity shoulder to the main line is present in the measured spectrum. Finally, the calculations for the $\mathrm{BrO}_{3}^{-}$predict two low-intensity satellites, both at low and high energy, at $-13 \mathrm{eV}$ and at $5.5 \mathrm{eV}$ from the main line. The experiment reveals such satellite lines at $-13.2 \pm 0.3$ $\mathrm{eV}$ and $4.1 \pm 0.2 \mathrm{eV}$. The main lines of $\mathrm{C}_{2} \mathrm{H}_{4} \mathrm{Br}_{2}$ and $\mathrm{BrO}_{3}^{-}$are approximately at the same energy in both experiment and theory. The description is not perfect though: the relative line intensities within a spectrum are not perfectly reproduced; also, the lines of the $\mathrm{Br}^{-}$are shifted lower from the main lines of the other two in the theory, which is not observed in the experiment. Nevertheless, the relevant features can be recognised in each pair of spectra, and their energy spacings compare fairly good. Consequently, the calculated spectra, although cannot serve as fingerprints, can be taken as very useful patterns that can help in the identification of a species.

This good agreement between experiment and theory suggests that, similar to the case of transition metal compounds $4,5,7,32,90,92$, reliable information can be obtained from the DFT calculations on the valence electron structure of $\mathrm{Br}$. In particular, the molecular orbital (MO) diagram can be directly compared to the experimental spectrum, and this provides insights for the interpretation of the experimental features. We demonstrate this on the example of $\mathrm{BrO}_{3}^{-}$, whose MO diagram for the highest occupied orbitals is displayed in figure 9. The MOs that give rise to the relevant valence-tocore XES peaks are shown separately in figure 10. Five transitions make up the calculated dipolar valence-to-core spectrum. The most intense feature at $13469 \mathrm{eV}$ arise from a bonding MO denoted as $\mathbf{B}$, which are made up by the combination of $\operatorname{Br}(p)$ and $\mathrm{O}(p)$ atomic orbitals; another $\operatorname{Br}(p)-\mathrm{O}(p)$ combination (A) appears as a high energy shoulder to the main peak at $13474.7 \mathrm{eV}$. The second most intense line at $13457 \mathrm{eV}$ arise from MO D, a bonding combination of $\operatorname{Br}(p)$ and $\mathrm{O}(s)$. The two weak features at $13452 \mathrm{eV}$ and $13461 \mathrm{eV}$, visible in the calculations but too small to be observed in the experimental spectrum, arise from MOs $\mathbf{C}$ and $\mathbf{E}$, which both result from the combinations of $\mathrm{O}(s)$ and $\operatorname{Br}(s)$ atomic orbitals. Finally, $\mathbf{F}$

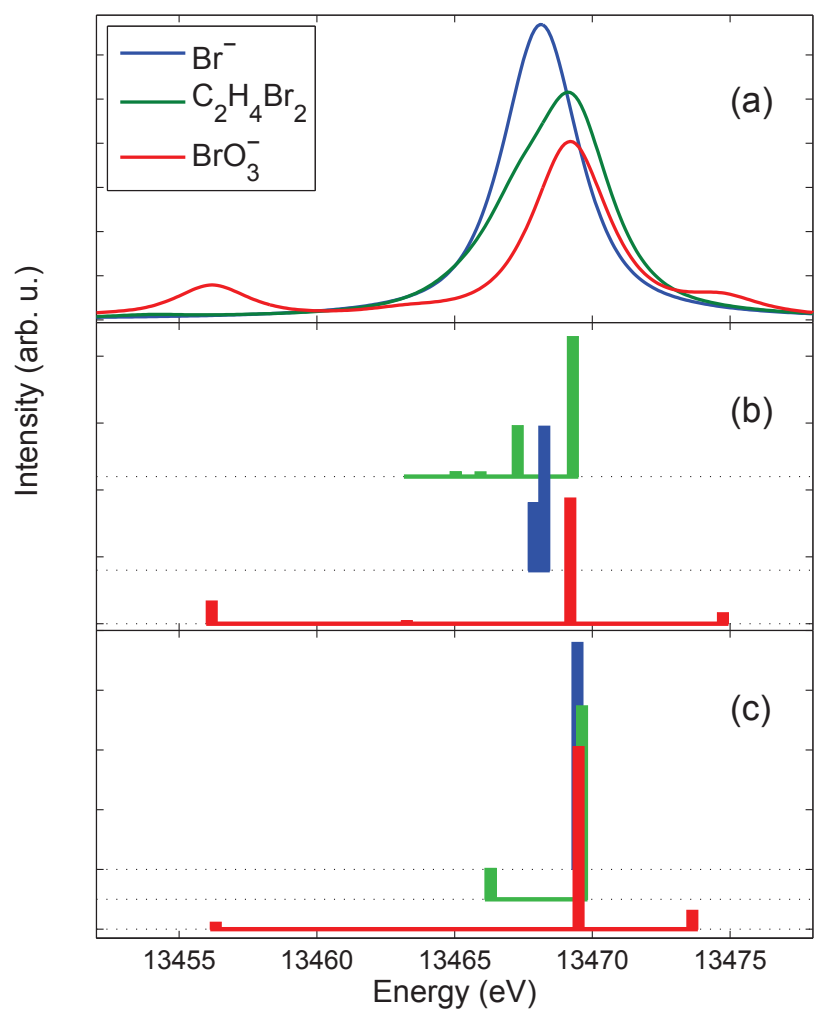

Fig. 8 Calculated valence-to-core emission spectra (panel a) and corresponding transitions (panel b) of $\mathrm{Br}^{-}, \mathrm{C}_{2} \mathrm{H}_{4} \mathrm{Br}_{2}$, and $\mathrm{BrO}_{3}^{-}$. The fitted line positions and intensities of the corresponding experimental spectra are represented as sticks in panel c. 


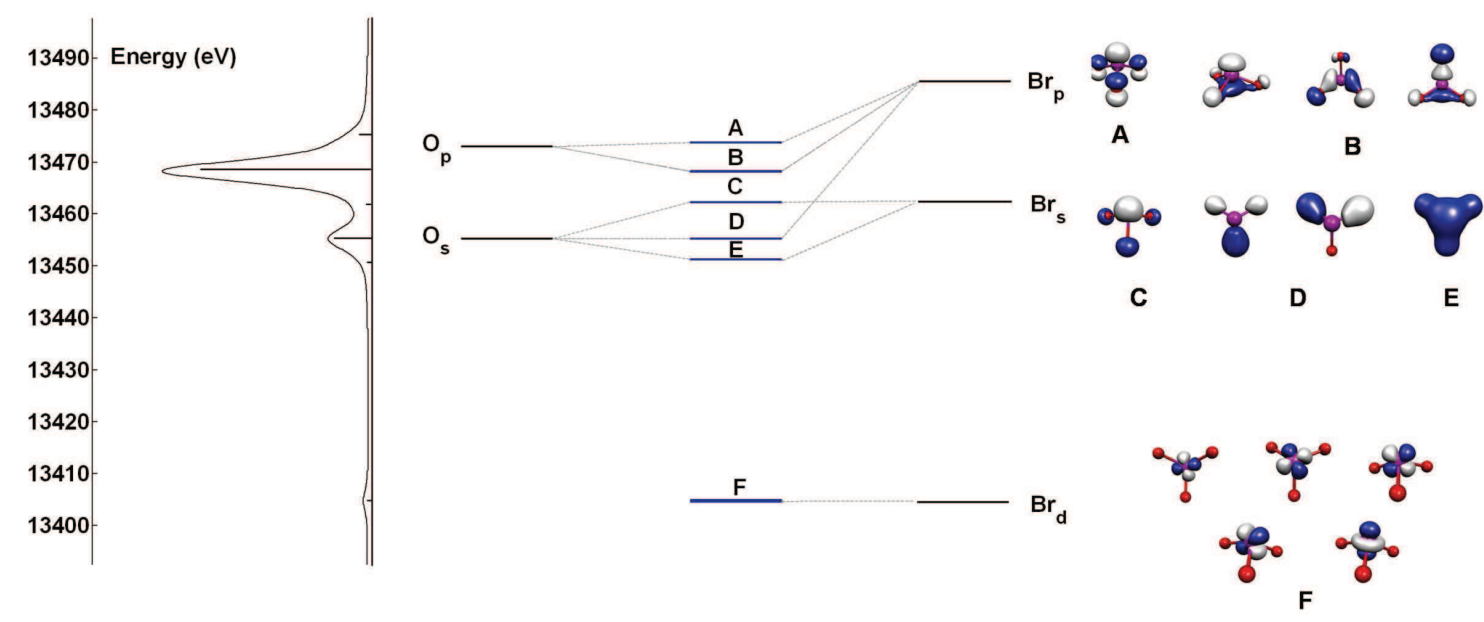

Fig. 10 MO diagram in the valence-to-core region, compared with the theoretical spectrum. The energy axis was shifted by $338 \mathrm{eV}$ to match the experimental values (see text for details).

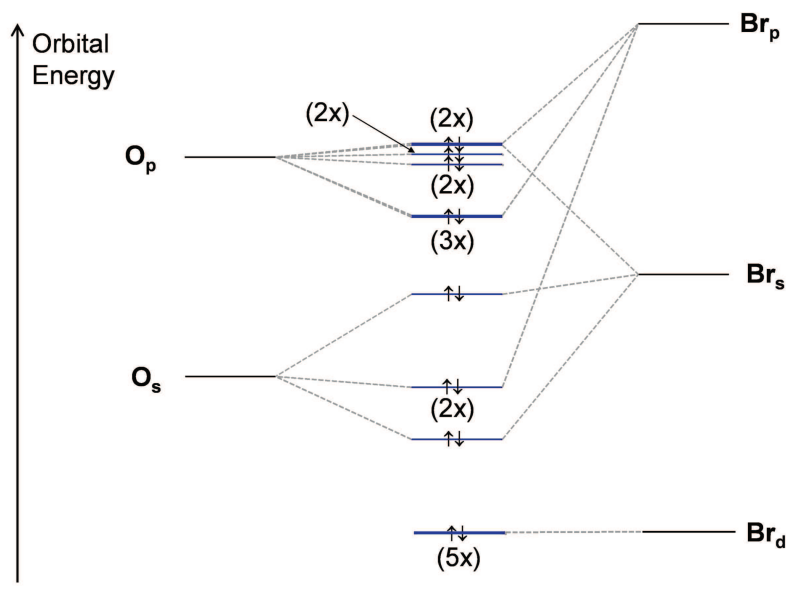

Fig. 9 Complete $\mathrm{MO}$ diagram of $\mathrm{BrO}_{3}^{-}$for the highest occupied orbitals, extracted from DFT calculations.

represents the non-bonding $d$ orbitals of $\mathrm{Br}$, which give rise to the weak quadrupole transitions at $13404 \mathrm{eV}$.

We have mentioned above that the final states in the valence-to-core XES and PES are identical, and therefore these techniques probe the same chemistry and physics, only the line shapes (intensities and broadenings) should differ, and for the XES the dipole selection rules apply. We compare the PES spectrum of $\mathrm{Br}_{2}$ to the calculated valence-to-core XES, to illustrate this point. The spectra, displayed in figure 11, are in excellent agreement with each other, justifying the very good correspondence between the two techniques. However, despite the experimental advantages of working with a hard $\mathrm{X}$-ray photon-in/photon-out spectroscopy technique, the core-

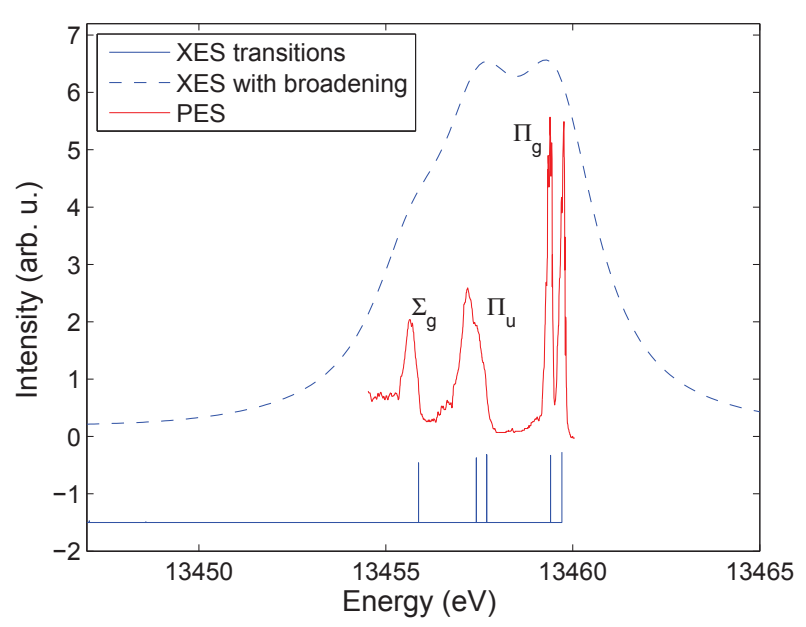

Fig. 11 Calculated valence-to-core spectrum of $\mathrm{Br}_{2}$ (dashed line) with the position of the corresponding transitions (sticks) and the photoemission spectrum (continuous line), adapted from Cornford and co-workers ${ }^{98}$.

hole lifetime broadenings are rather large for the $\mathrm{Br} 1 s$ XES, which makes resolving the individual features difficult. The spectrum in the figure was created using a Lorentzian broadening of $2.5 \mathrm{eV}$ (for the $1 s$ core-hole lifetime), and a Gaussian with a FWHM of $0.5 \mathrm{eV}$ (for instrumental broadening). Therefore, it reflects a spectra that is close to the best resolved in a real experiment. Nevertheless, despite the broad lines, in many investigations this technique can be used advantageously to get chemically relevant information, which we further explore in what follows. 
The valence-to-core XES for the extended series of $\mathrm{Br}$ bearing compounds is presented in figure 12. The first group comprises organic covalent compounds of $\mathrm{Br}$, including aliphatic and aromatic bromides. Despite the clear differences in the calculated spectra (Fig. 12a), it might not be straightforward to experimentally distinguish the relatively low variations in energy and intensity of the spectral features. The overall shape of the spectra is indeed very broad for the different compounds, and, except for EtMgBr, the energy position of the most intense peak are rather close. The second group includes inorganic compounds with various oxidation states of $\mathrm{Br}$. In the case of $\mathrm{Br}^{-}$ion (oxidation state -1 ), the spectrum is characterized by a single peak. $\mathrm{HBr}$ displays a feature similar to the peak of $\mathrm{Br}^{-}$in intensity, but it is shifted in energy, and a second peak at lower energy can also be seen, due to effects of the bonding to the hydrogen. If in the diatomic molecule we replace $\mathrm{H}$ with $\mathrm{F}$, which has much higher electronegativity, the spectral shape remains very similar, but it is shifted reflecting the decreased electron density on the Br. For the rest, we observe that the shifts or splittings increase with the oxidation state of Br: a splitting is barely visible for the $\mathrm{Br}$ atom (oxidation state 0 ), one broad feature characterized by two separated humps is found for $\mathrm{BrO}$ (oxidation state +2 ), two features split by $7 \mathrm{eV}$ is seen for $\mathrm{BrF}_{3}$ (oxidation state +3 ) and two features split by more than $10 \mathrm{eV}$ for $\mathrm{BrO}_{4}^{-}$(oxidation state +7 ) (Fig. $12 \mathrm{~b}$ ). It would of course be easy to plot the MO diagram for each of these compounds, and relate all spectral features to the MOs, similar to the case of the $\mathrm{BrO}_{3}^{-}$; however, to discuss the applicability of the technique the phenomenological description of the variations of the spectral shapes should suffice. Such variations suggest that these features will be easily resolved during experiments, and that they will enable a direct analysis of the chemical state of inorganic $\mathrm{Br}$ compounds.

Due to the recent developments of highly efficient crystal spectrometers ${ }^{75,99-103}$, these low-fluorescence-yield features can be collected with acceptable count rates. With the combination of experiment and theory, the valence-to-core emission spectroscopy thus appears as a powerful X-ray technique to probe the chemical state of an element. It is used more and more often to investigate transition metals and their ligands in molecular complexes $2,5,7,32,90,92$, with the help of theoretical calculations that enable us to extract the MO diagram, and thus the experimental features can be interpreted in terms of chemical bonding. The advantages of using hard X-rays will allow us to use this technique to study materials in situ under extreme conditions, or during chemical transformations, even on the ultrafast time scale (fs or ps). The application of (core-tocore) XES as a probe in ultrafast pump-and-probe experiments has commenced ${ }^{69,72,73}$, however, the chemical sensitivity of valence-to-core emission spectroscopy is expected to lead to milestones in the deeper understanding of the elementary steps of ultrafast processes. This includes photochemical transitions
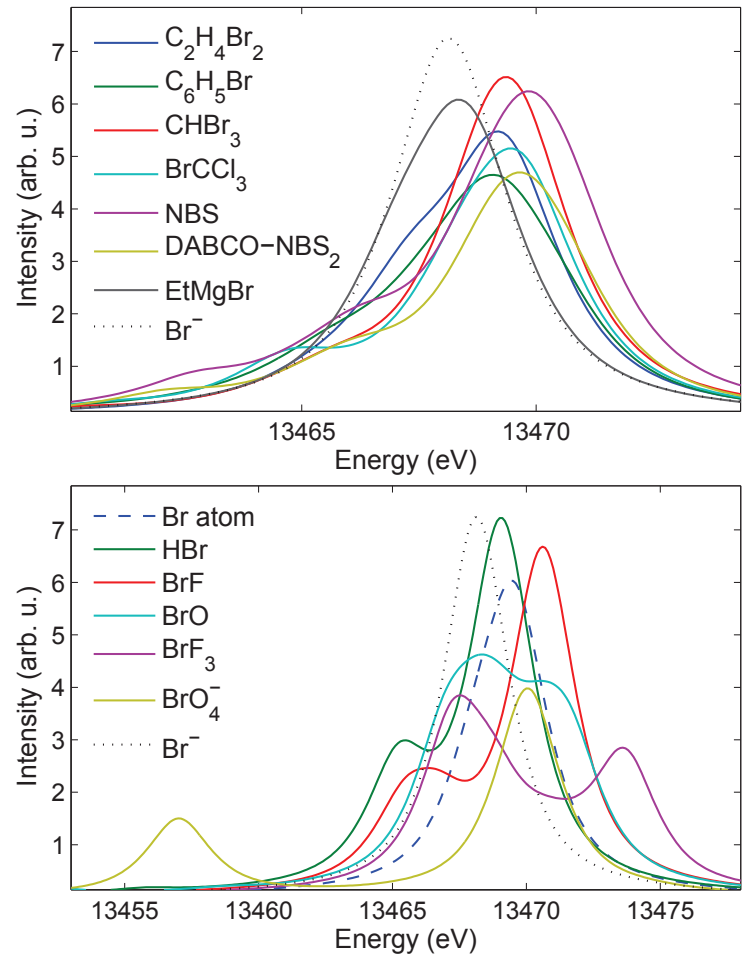

Fig. 12 Calculated valence-to-core spectra of the extended series of organic (a) and inorganic (b) Br-compounds. The spectrum of $\mathrm{Br}^{-}$ is shown on both figures as a reference.

of Br-bearing compounds, for which time-resolved XAS and $\mathrm{X}$-ray scattering investigations have already started ${ }^{67,68}$.

\section{Conclusions}

A combined experimental and theoretical study was performed to evaluate the sensitivity of hard X-ray spectroscopies at the K edge, HERFD-XAS and XES, to the chemical state of Br. Concerning XAS, we demonstrated that the use of a high-resolution crystal spectrometer allows us to obtain significantly better resolved $\mathrm{Br} \mathrm{K}$-edge spectra by recording HERFD-XAS scans. For the case of $\mathrm{Br}$, the $\mathrm{K} \alpha$ - and $\mathrm{K} \beta$ HERFD spectra are fairly similar, and thus using any of these detection channels can be equally advantageous. With XES, the experimental data, and the DFT calculations both show that the $\mathrm{K} \alpha$ and $\mathrm{K} \beta_{1,3}$ emission lines present little variations for the different chemical states of Br. In contrast, the valence-to-core spectra display significant variations in the number of observed features, energy positions and intensities, as expected from a technique that gives access to the occupied molecular orbitals similar to photoemission spectroscopy. Although the large lifetime broadening smears some of the details, this part of the spectrum offers the means to characterize 
the electronic structure of $\mathrm{Br}$ with hard X-rays, similarly to recent examples on transition metal compounds.

With the combination of experiment and DFT calculations, the valence-to-core emission spectroscopy appears very promising for chemical analysis at modern synchrotron radiation and X-ray free electron laser facilities. The advantages of using hard X-rays will allow the in situ study of materials under extreme conditions or during chemical transformations, even on the ultrafast time scales.

\section{Acknowledgments}

This work was supported by the European Research Council via contract ERC-StG 259709. The authors thank Frank Neese (Max-Planck-Institut für Chemische Energiekonversion) for fruitful discussion, Roberto Verbeni (ESRF) for making the analyzer crystals available, the SuperXAS beamline staff and SLS support groups for technical assistance during experiments. GV acknowledges support from the Bolyai János fellowship of the Hungarian Academy of Sciences.

\section{References}

1 U. Bergmann and P. Glatzel, Photosynthesis Research, 2009, 102, 255 266.

2 P. Glatzel and U. Bergmann, Coordination Chemistry Review, 2005, 249, 65-95.

3 G. Vankó, T. Neisius, G. Molnár, F. Renz, S. Kárpáti, A. Shukla and F. F. de Groot, Journal of Physical Chemistry B, 2006, 110, 11647-11653.

4 G. Smolentsev, A. V. Soldatov, K. Messinger, Johannesand Merz, T. Weyhermüller, U. Bergmann, Y. Pushkar, J. Yano, V. K. Yachandra and P. Glatzel, Journal of the American Chemical Society, 2009, 131, 13161-13167.

5 N. Lee, T. Petrenko, U. Bergmann, F. Neese and S. DeBeer, Journal of the American Chemical Society, 2010, 132, 9715-9727.

6 R. Alonso Mori, E. Paris, G. Giuli, S. Eeckhout, M. Kavcic, M. Zitnik, K. Bucar, L. Pettersson and P. Glatzel, Inorganic Chemistry, 2010, 49, 6468-6473.

7 M. A. Beckwith, M. Roemelt, M.-N. Collomb, C. DuBoc, T.-C. Weng, U. Bergmann, P. Glatzel, F. Neese and S. DeBeer, Inorganic Chemistry, 2011, 50, 8397-8409.

8 C. J. Doonan, L. Zhang, C. G. Young, S. J. George, A. Deb, U. Bergmann, G. N. George and S. P. Cramer, Inorg. Chem.; (Communication), 2005, 44, 2579-2581.

9 F. de Groot, Coordination Chemistry Review, 2005, 249, 31-63.

10 T. E. Westre, P. Kennepohl, J. G. DeWitt, B. Hedman, K. O. Hodgson and E. I. Solomon, Journal of the American Chemical Society, 1997, 119, 6297-6314.

11 M.-A. Arrio, S. Rossano, C. Brouder, L. Galoisy and G. Calas, Europhysics Letters, 2000, 51, 454-460.

12 S. DeBeer George, P. Brant and E. Solomon, Journal of the American Chemical Society, 2005, 127, 667-674.

13 F. Farges, Physical Review B, 2005, 71, 155109

14 A. Shukla, M. Calandra, M. Taguchi, A. Kotani, G. Vankó and S.-W. Cheong, Physical Review Letters, 2006, 96, 077006.

15 A. Juhin, C. Brouder, M.-A. Arrio, D. Cabaret, P. Sainctavit, E. Balan, A. Bordage, A. P. Seitsonen, G. Calas, S. G. Eeckhout and P. Glatzel, Physical Review B, 2008, 78, 195103.
16 A. Kotani, K. Okada, G. Vankó, G. Dhalenne, A. Revcolevschi, P. Giura and A. Shukla, Phys. Rev. B, 2008, 77, 205116.

17 F. de Groot, G. Vankó and P. Glatzel, Journal of Physics: Condensed Matter, 2009, 21, 104207 (7pp).

18 F. Farges, Physics and Chemistry of Minerals, 2009, 36, 463-481.

19 A. Bordage, C. Brouder, E. Balan, D. Cabaret, A. Juhin, M.-A. Arrio, P. Sainctavit, G. Calas and P. Glatzel, American Mineralogist, 2010, 95, 1161-1171.

20 D. Cabaret, A. Bordage, A. Juhin, M. Arfaoui and E. Gaudry, Physical Chemistry Chemical Physics, 2010, 12, 5619-5633.

21 A. Juhin, F. de Groot, G. Vankó, M. Calandra and C. Brouder, Physical Review B, 2010, 81, 115115.

22 J. J. Rehr, J. J. Kas, F. D. Vila, M. P. Prange and K. Jorissen, Physical Chemistry and Chemical Physics, 2010, 12, 5503-5513.

23 R. Laskowski and P. Blaha, Physical Review B, 2010, 82, 205104.

24 S. DeBeer and F. Neese, Inorganic Chemistry, 2010, 49, 1849-1853.

25 P. Glatzel, J. BSingh, K. O. Kvashnina and J. A. van Bokhoven, Journal of the American Chemical Society, 2010, 132, 2555-2557.

26 J. Kas, J. J. Rehr, J. Soininen and G. Pieter, Physical Review B, 2011, 83, 235114.

27 N. Trcera, S. Rossano, K. Madjer and D. Cabaret, Journal of Physics: Condensed Matter, 2011, 323, 255401.

28 A. Bordage, S. Rossano, A. Horn and Y. Fuchs, Journal of Physic:Condensed Matter, 2012, 24, 225401.

29 M. Roemelt, M. A. Beckwith, C. Duboc, M.-N. Collomb, F. Neese and S. DeBeer, Inorganic Chemistry, 2012, 51, 680-687.

30 G. Peng, F. de Groot, K. Hämäläinen, J. Moore, X. Wang, M. Grush, J. Hastings, D. Siddons, W. Amstrong, O. Mullins and S. Cramer, J. Am. Chem. Soc., 1994, 116, 2914-2920.

31 X. Wang, F. M. F. de Groot and S. P. Cramer, Phys. Rev. B, 1997, 56, 4553-4564.

32 K. M. Lancaster, K. D. Finkelstein and S. DeBeer, Inorganic Chemistry, 2011, 50, 6767-6774.

33 K. Hämäläinen, D. P. Siddons, J. B. Hastings and L. E. Berman, Physical Review Letters, 1991, 67, 2850.

34 F. de Groot and A. Kotani, Core Level Spectroscopy of Solids, Taylor \& Francis, New York, 2008.

35 P. Carra, M. Fabrizio and B. T. Thole, Physical Review Letters, 1995 , 74, 3700-3703.

36 J. Yano and V. K. Yachandra, Photosynthesis Review, 2009, 102, 241254.

37 A. Bordage, E. Balan, J. P. de Villiers, R. Cromarty, A. Juhin, C. Carvallo, G. Calas, P. S. Raju and P. Glatzel, Physics and Chemistry of Minerals, 2011, 38, 449-458.

38 R. Alonso Mori, E. Paris, G. Giuli, S. Eeckhout, M. Kavcic, M. Zitnik, K. Bucar, L. Pettersson and P. Glatzel, Analytical Chemistry, 2009, 81, 6516-6525.

39 J. C. Swarbick, U. Skyllberg, T. Karlsson and P. Glatzel, Inorganic Chemistry, 2009, 48, 10748-10756.

40 F. M. F. de Groot, M. H. Krisch and J. Vogel, Phys. Rev. B, 2002, 66, 195112.

41 O. Safonova, M. Tromp, J. van Bokhoven, J. de Groot, F.M.Fand Evans and P. Glatzel, Journal of Physical Chemistry B, 2006, 110, 16162 16164.

42 A. Kotani, K. O. Kvashnina, P. Glatzel, J. C. Parlebas and G. Schmerber, Phys. Rev. Lett., 2012, 108, 036403.

43 B. M. Kincaid and P. Eisenberger, Physical Review Letters, 1975, 34, 1361-1364.

44 A. Fontaine, P. Lagarde, D. Raoux, M. Fontana, G. Maisano, P. Migliardo and F. Wanderlingh, Physical Review Letters, 1978, 41, 504-507.

45 A. San Miguel, H. Libotte, J.-P. Gaspard, M. Gauthier, J.-P. Itié and 
A. Polian, European Physics Journal B, 2000, 17, 227-233.

46 V. Simonet, Y. Calzavara, J.-L. Hazemann, R. Argoud, O. Geaymond and D. Raoux, Journal of Chemical Physics, 2002, 116, 2997-3006.

47 V. Simonet, Y. Calzavara, J.-L. Hazemann, R. Argoud, O. Geaymond and D. Raoux, Journal of Chemical Physics, 2002, 117, 2771-2781.

48 Y. Chen, J. L. Fulton and W. Partenheimer, Journal of the American Chemical Society, 2005, 127, 14085-14093.

49 A. San Miguel, H. Libotte, M. Gauthier, G. Aquilanti, S. Pascarelli and J.-P. Gaspard, Physical Review Letters, 2007, 99, 015501.

50 C. G. Elles, I. A. Shkrob, R. A. Crowell, D. A. Arms and E. C. Landahl, The Journal of Chemical Physics, 2008, 128, 061102.

51 C. Da Silva, O. Proux, J.-L. Hazemann, J. James-Smith, D. Testemale and T. Yamaguchi, Journal of Molecular Liquids, 2009, 147, 83-95.

52 P. d'Angelo, A. Di Cicco, A. Filipponi and N. Pavel, Physical Review A, 1993, 47, 2055-2063.

53 Y. Ito, T. Mukoyama, S. Emura, M. Takahashi, S. Yoshikado and K. Omote, Physical Review A, 1995, 51, 303-308.

54 K. Evans, J. Mavrogenes and M. Newville, Journal of Synchrotron Radiation, 2005, 14, 219-226.

55 M. Bergknut, P. Persson and U. Skyllberg, Analytical and Bioanalytical Chemistry, 2008, 390, 921-928.

56 N. Greenwood and A. Earnshaw, Chemistry of the elements (2 ${ }^{\text {nd }}$ Edition), Elsevier, 1997.

57 M. Scarratt and R. Moore, Marine Chemistry, 1998, 59, 311-320.

58 D. Seyferth, Organometallics, 2003, 22, 5154-5178.

59 M. Rusu, I. Ichim, M. Popa and M. Rusu, Journal of Materials Science: Materials in Medicine, 2008, 19, 2609-2617.

60 L. Ferry, J. Lopez Cuesta, C. Chivas, G. Mac Way Hoy and H. Dvir, Polymer Degradation and Stability, 2001, 74, 449-456.

61 S. Vassilev, G. Eskenazy and C. Vassileva, Fuel, 2000, 79, 903-921.

62 S. Vassilev, G. Eskenazy and C. Vassileva, Fuel, 2000, 79, 923-937.

63 C. A. de Wit, Chemosphere, 2002, 46, 583-624.

64 R. J. Law, M. Kohler, N. V. Heeb, A. C. Gerecke, P. Schmid, S. Voorspoels, A. Covaci, G. Becher, K. Janák and C. Thomsen, Environmental Science and Technology, 2005, 39, 281A-287A.

65 V. Grignard, Compte-Rendu Hebdomadaire de l'Académie des Sciences, 1900, 130, 1322-1324.

66 D. Oulianov, I. Tomov, A. Dvornikov and P. Rentzepis, PNAS, 2002, 99, 12556-12561.

67 W. Li, A. A. Jarón-Becker, C. W. Hogle, V. Sharma, X. Zhou, A. Becker, H. C. Kapteyn and M. M. Murnane, PNAS, 2010, 107, 20219-20222.

68 Q. Kong, L. J. Hyuk, M. Lo Russo, T. K. Kim, M. Lorenc, M. Cammarata, S. Bratos, T. Buslaps, V. Honkimaki, H. Ihee and M. Wulff, Acta Crystallographica A, 2010, 66, 252-260.

69 G. Vankó, P. Glatzel, V.-T. Pham, R. Abela, D. Grolimund, C. N. Borca, S. L. Johnson, C. J. Milne and C. Bressler, Angewandte Chemie International Edition, 2010, 49, 5910-5912.

70 C. Bressler, C. Milne, V.-T. Pham, A. ElNahhas, R. van der Veen, W. Gawelda, S. Johnson, P. Beaud, D. Grolimund, M. Kaiser, C. Borca, G. Ingold, R. Abela and M. Chergui, Science, 2009, 323, 489-492.

71 M. Chergui, Acta Crystallographica Section A, 2010, 66, 229-239.

72 G. Vankó, A. Bordage, P. Glatzel, E. Gallo, M. Rovezzi, W. Gawelda, A. Galler, C. Bressler, G. Doumy, A. M. March, E. P. Kanter, L. Young, S. H. Southworth, S. E. Canton, J. Uhlig, G. Smolentsev, V. Sundstrm, K. Haldrup, T. B. van Driel, M. M. Nielsen, K. S. Kjaer and H. T. Lemke, Journal of Electron Spectroscopy and Related Phenomena, 2012.

73 K. Haldrup, G. Vankó, W. Gawelda, A. Galler, G. Doumy, A. M. March, E. P. Kanter, A. Bordage, A. Dohn, T. B. van Driel, K. S. Kj?r, H. T. Lemke, S. E. Canton, J. Uhlig, V. Sundström, L. Young, S. H. Southworth, M. M. Nielsen and C. Bressler, The Journal of Physical Chemistry A, 2012, 116, 9878-9887.

74 E. Kleymenov, A. Bergamaschi, J. van Bokhoven, M. Janousch,
B. Schmitt and M. Nachtegaal, Journal of Physics: Conference Series, 2009, 190, 012035.

75 E. Kleymenov, J. van Bokhoven, C. David, P. Glatzel, M. Janousch, R. Alonso Mori, M. Studer, M. Willimann, A. Bergamaschi, B. Henrich and M. Nachtegaal, Review of Scientific Instruments, 2011, 82, 065107.

76 P. Chand and G. Upreti, Journal of Chemical Physics, 1985, 83, 3744 3748.

77 S. Abrahams and J. Bernstein, Acta Crystallographica B, 1977, 33, 3601-3604.

78 F. Neese, U. Becker, D. Ganyushin, A. Hansen, D. Liakos, C. Kollmar, S. Kossmann, T. Petrenko, C. Reinmann, C. Riplinger, K. Sivalingam, E. Valeev, B. Wezisla and F. Wennmohs, PhD thesis, University of Bonn, Bonn, Germany, 2010.

79 A. Becke, Physical Review A, 1988, 38, 5648-5652.

80 P. Stephens, F. Devlin, C. Chabalowski and M. Frisch, Journal of Physical Chemistry, 1994, 98, 11623-11627.

81 A. Schaefer, H. Horn and R. Alrichs, Journal of Chemical Physics, 1992, 97, 2571-2577.

82 P. Pulay, Chemical Physics Letters, 1980, 73, 393-398.

83 M. U. Delgado-Jaime and S. DeBeer, Journal of Computational Chemistry, 2012, 33, 2180-2185.

84 F. M. F. de Groot, Chem. Rev., 2001, 101, 1779-1808.

85 M. Krause and J. Oliver, Journal of Physical and Chemical Reference Data, 1979, 8, 329-338.

86 J. C. Fuggle and S. F. Alvarado, Physical Review A, 1980, 22, 1615 1624.

87 L.-Å. Näslund, J. Lüning, Y. Ufuktepe, H. Ogasawara, P. Wernet, U. Bergmann, L. Pettersson and A. Nilsson, Journal of Physical Chemistry $B, 2005,109,13835-13839$.

88 P. Glatzel, G. Smolentsev and G. Bunker, Journal of Physics: Conference Series, 2009, 190, 012046.

89 U. Bergmann, C. Horne, T. Collins, J. Workman and S. Cramer, Chem. Phys. Lett., 1999, 302, 119-124.

90 U. Bergmann, J. Bendix, P. Glatzel, H. B. Gray and S. P. Cramer, J. Chem. Phys., 2002, 116, 2011-2015.

91 V. Safonov, L. Vykhodtseva, Y. Polukarov, O. Safonova, G. Smolentsev, M. Sikora, S. Eeckhout and P. Glatzel, Journal of Physical Chemistry B 2006, 110, 23192-23196.

92 C. J. Pollock and S. DeBeer, Journal of the American Chemical Society, 2011, 133, 5594-5601.

93 J.-P. Rueff, C.-C. Kao, V. V. Struzhkin, J. Badro, J. Shu, R. J. Hemley and H. K. Mao, Physical Review Letters, 1999, 82, 3284-3287.

94 J.-P. Rueff, A. Mattila, J. Badro, G. Vankó and A. Shukla, J. Phys.: Condens. Matter, 2005, 17, S717-S726.

95 S. DeBeer, T. Petrenko and F. Neese, Journal of Physical Chemistry A, 2008, 112, 12936-12943.

96 F. Neese, Coordination Chemistry Review, 2009, 253, 526-563.

97 K. Raatikainen and K. Rissanen, CrystEngComm, 2011, 13, 6972-6977.

98 A. Cornford, D. Frost, C. McDowell, J. Ragle and I. Stenhouse, The Journal of Chemical Physics, 1971, 54, 2651-2657.

99 P. Glatzel, M. Sikora, G. Smolentsev and M. Fernández-García, Catalysis Today, 2009, 145, 294-299.

100 R. Alonso Mori, J. Kern, D. Sokaras, T.-C. Weng, D. Nordlund, R. Tran, P. Montanez, J. Delor, V. K. Yachandra, J. Yano and U. Bergmann, Review of Scientific Instruments, 2012, 83, 073114.

101 J. Szlachetko, M. Nachtegaal, E. de Boni, M. Willimann, O. Safonova, J. Sa, G. Smolentsev, M. Szlachetko, J. A. van Bokhoven, J.-C. Dousse, J. Hoszowska, Y. Kayser, P. Jagodzinski, A. Bergamaschi, B. Schmitt, C. David and A. Lücke, Review of Scientific Instruments, 2012, 83, 103105 .

102 K. M. Davis, B. A. Mattern, J. I. Pacold, T. Zakharova, D. Brewe, I. Kosheleva, R. W. Henning, T. J. Graber, S. M. Heald, G. T. Seidler 
and Y. Pushkar, The Journal of Physical Chemistry Letters, 2012, 3, $1858-1864$.

103 B. A. Mattern, G. T. Seidler, M. Haave, J. I. Pacold, R. A. Gordon, J. Planillo, J. Quintana and B. Rusthoven, Review of Scientific Instruments, 2012, 83, 023901. 